\title{
Characterization of an Acidic Arabinoxylan from Cell Walls of Immature Barley Plants ${ }^{\dagger}$
}

\author{
Yoji Kato, ${ }^{*}$ Katsuhiro IKI** and Kazuo MatsudA*** \\ Department of Agricultural Chemistry, Faculty of Agriculture, \\ Tohoku University, Tsutsumidori, Sendai 980, Japan
}

Received September 10, 1987

\begin{abstract}
An acidic arabinoxylan occurring in the hemicellulose I fraction $(4 \%$ potassium hydroxide extract) of cell walls of immature barley plants was isolated and characterized by methylation and fragmentation analyses. The results indicated that the acidic arabinoxylan had a linear backbone chain of $\beta-1,4-D$-xylose residues, about $50 \%$ of which were substituted at the 2 and/or 3 position, mainly with arabinofuranose and glucuronic acid residues.
\end{abstract}

To characterize polysaccharides in the cell walls of immature barley plants, we separated them into six fractions using successive extraction with ammonium oxalate-oxalic acid, $4 \%$ potassium hydroxide, and $24 \%$ potassium hydroxide. We reported earlier the chemical structure of the $\beta$-D-glucan obtained from the hemicellulose I fraction, a polysaccharide fraction extracted with $4 \%$ potassium hydroxide, and that of the xyloglucan obtained from the hemicellulose II fraction, a polysaccharide fraction extracted with $24 \%$ potassium hydroxide. ${ }^{1,2)}$ Furthermore, we reported that the hemicellulose I fraction obtained from barley cell walls contained $\beta$-D-glucan and arabinoxylan in the approximate ratio of $30 \sim 40: 60 \sim 70 .{ }^{1)}$ This paper describes the chemical structure of arabinoxylan, another predominant polysaccharide of barley cell walls.

\section{MATERIALS AND METHODS}

Materials. The polysaccharides in cell walls of immature barley plants were separated into six fractions; PS, HC-IA,
HC-IB, HC-IIA, HC-IIB, and CL, and then HC-IB was fractionated into six subfractions ( $\mathrm{HC}-\mathrm{IB}-1$ to -6 ) by graded ammonium sulfate precipitation as described in our previous paper. ${ }^{1)}$ This study used fraction HC-IB-6, which consisted of arabinose, xylose, glucose, and galactose in the molar ratio of $36.2: 54.1: 3.7: 6.3$. The endo- $\beta$ 1,4-xylanase from Streptomyces sp. (128 units $/ \mathrm{mg}$ ) was the same as reported previously. ${ }^{3)}$ 4-O- $\beta$-D-Xylopyranosyl-Dxylose was prepared from the enzymic hydrolyzate of rice straw $\beta$-1,4-xylan (our laboratory collection). Bio-Gel P-2 (200 400 mesh) - was purchased from Bio-Rad, and Sepharose CL-6B, DEAE-Cellulose, Blue dextran, and Dextrans T-500, T-250, T-110, T-70, and T-40 were from Pharmacia Fine Chemicals.

General methods. Carbohydrate solutions were concentrated under reduced pressure at $40 \sim 45^{\circ} \mathrm{C}$. Ascending paper chromatography was done on Toyo No. 50 filter paper using butanol-pyridine-water $(6: 4: 3, \mathrm{v} / \mathrm{v})$ (method A) or by the descending method using ethyl acetatewater-acetic acid-formic acid (18:4:3:1, v/v) (method B). Sugars on the chromatogram were detected with alkaline silver nitrate. ${ }^{4)}$ Optical rotation was measured with a Nippon Bunko Model DIP-SL polarimeter. Gasliquid chromatography (GLC) was done with a Yanagimoto Model G-80 gas chromatograph with a flame ionization detector at a nitrogen gas flow of $15 \mathrm{ml}$ per min, on a glass column $(0.4 \times 200 \mathrm{~cm})$ of $1.5 \% \mathrm{QF}-1$ on Chromosorb W (AW-DMCS) [column (a)] or a glass column $(0.4 \times 200 \mathrm{~cm})$ of $3 \%$ OV-210 on Supelcoport

+ Cell-wall Polysaccharides of Immature Barley Plants. Part III. For Part II, see ref. 2.

* Present address: Laboratory of Food Science, Faculty of Education, Hirosaki University, Hirosaki 036, Japan. To whom all correspondence should be addressed.

** Present address: Miyagi Prefectural Office, Sendai 980, Japan

*** Present address: Iwaki Meisei University, Iwaki 970, Japan. 
[column (b)]. Total carbohydrate was measured by the phenol-sulfuric acid method. ${ }^{5)}$

Analysis of neutral sugars in poly-or oligo-saccharide fraction. Polysaccharide $(1 \sim 2 \mathrm{mg})$ was hydrolyzed with $1 \mathrm{M}$ sulfuric acid for $5 \sim 6 \mathrm{hr}$ at $100^{\circ} \mathrm{C}$, and oligosaccharide $(0.2 \sim 1 \mathrm{mg})$ was hydrolyzed with $0.5 \mathrm{~m}$ sulfuric acid for $3 \sim 4 \mathrm{hr}$ at $100^{\circ} \mathrm{C}$. Each hydrolyzate was neutralized with barium carbonate, treated with Amberlite IR-120 resins $\left(\mathrm{H}^{+}\right.$form) to remove barium ions and then concentrated. Sugars were analyzed by GLC on column (a) at $140^{\circ} \mathrm{C}$ after converting them to alditol trifiuoroacetates. ${ }^{6)}$

Chromatography of fraction $H C-I B-6$ on $D E A E-$ Cellulose. HC-IB-6 (500 $\mathrm{mg})$ was dissolved in $50 \mathrm{ml}$ of distilled water and centrifuged. The supernatant was put on a column $(1.5 \times 25 \mathrm{~cm})$ of DEAE-Cellulose (acetate form), and eluted stepwise with water $(75 \mathrm{ml}$, fraction $\mathrm{HC}$ IB-6-i), $50 \mathrm{~mm}$ potassium acetate $(66 \mathrm{ml}, \mathrm{HC}-\mathrm{IB}-6-\mathrm{ii}), 0.1 \mathrm{M}$ potassium acetate $(144 \mathrm{ml}, \mathrm{HC}-\mathrm{IB}-6-\mathrm{iii}), 0.5 \mathrm{M}$ potassium acetate (105 ml, HC-IB-6-iv), $0.1 \mathrm{M}$ sodium hydroxide (72 ml, HC-IB-6-v), $0.2 \mathrm{M}$ sodium hydroxide $(66 \mathrm{ml}, \mathrm{HC}$ IB-6-vi), and $0.5 \mathrm{~m}$ sodium hydroxide $(69 \mathrm{ml}$, HC-IB-6vii). These seven fractions were separately freeze-dried, following neutralization, dialysis against deionized water, and concentration. Yields of fractions HC-IB-6-i to -vii were $21,42,151,217,14,10$, and $10 \mathrm{mg}$, respectively. Fraction HC-IB-6-iv was further studied as an acidic arabinoxylan $(\mathrm{A}-\mathrm{AX})$ from cell walls of immature barley plants.

High voltage paper electrophoresis of $A-A X$. A-AX (5 mg in $0.1 \mathrm{ml}$ of water) was put on a line $20 \mathrm{~cm}$ from the anodal end of a $5 \times 60 \mathrm{~cm}$ strip of Toyo GA-100 glass filter paper soaked in $0.1 \mathrm{M}$ sodium tetraborate $(\mathrm{pH}$ 9.3). Electrophoresis was done at $1350 \mathrm{v}$ for $70 \mathrm{~min}$ in a high voltage paper electrophoresis apparatus HPE-V (Toyo Kagaku). After electrophoresis, the filter paper was cut into strips $(5 \times 1 \mathrm{~cm})$. Each strip was soaked in $2 \mathrm{ml}$ of deionized water, heated in a boiling-water bath for $5 \mathrm{~min}$, and filtered on Toyo No. 2 filter paper. The carbohydrate in the filtrate was measured by the phenol-sulfuric acid method.

Gel filtration of $A-A X$ on Sepharose $C L-6 B$. A-AX $(2 \mathrm{mg})$ in $0.1 \mathrm{M}$ sodium hydroxide $(0.3 \mathrm{ml})$ was put on a column $(1.5 \times 72 \mathrm{~cm})$ of Sepharose CL- $6 \mathrm{~B}$ pre-equilibrated with $0.1 \mathrm{M}$ sodium hydroxide, followed by filtration through the column with $0.1 \mathrm{~m}$ sodium hydroxide. Fractions of $1 \mathrm{ml}$ each were collected and assayed for carbohydrate. The column had been calibrated using Blue dextran, Dextrans T-500, T-250, T-110, T-70, and $\mathrm{T}-40$, and glucose.

Sugar analysis of $A-A X$. A-AX (15 mg) was hydrolyzed with $2 \mathrm{ml}$ of $0.5 \mathrm{M}$ sulfuric acid for $14 \mathrm{hr}$ at $100^{\circ} \mathrm{C}$. The hydrolyzate was neutralized with barium carbonate and filtered. The filtrate was passed through a column $(0.4 \times 6 \mathrm{~cm})$ of Dowex-1 (acetate form), yielding the neutral sugar fraction: Acidic sugars were eluted from the column with $6 \mathrm{M}$ acetic acid. Yields of the neutral and acidic fractions were 11.4 and $1.4 \mathrm{mg}$, respectively. Neutral sugars were analyzed by GLC as described under "Analysis of neutral sugars in poly- or oligo-saccharide fractions." Acidic sugars were analyzed by paper chromatography (method B).

Methylation analysis of $A-A X . \mathrm{A}-\mathrm{AX}(10 \mathrm{mg})$ dissolved in dimethyl sulfoxide $(3 \mathrm{ml})$ was methylated using methylsulfinyl carbanion $(0.5 \mathrm{ml})$ and methyl iodide $(0.5 \mathrm{ml})$ by the method of Hakomori, ${ }^{7)}$ and then dialyzed against tap water. The non-dialyzable materials were concentrated to dryness. The methylated A-AX was methylated twice more. The methylated A-AX was hydrolyzed with $90 \%$ $\mathrm{HCOOH}-0.25 \mathrm{M}$ sulfuric acid and converted into the corresponding alditol acetates. ${ }^{8)}$ The partially methylated alditol acetates were analyzed by GLC on column (b) at $172^{\circ} \mathrm{C}$.

Partial acid hydrolysis of $A-A X$ and resolution of the hydrohyzate. A-AX $(100 \mathrm{mg})$ in $15 \mathrm{ml}$ of $50 \mathrm{~mm}$ trifluoroacetic acid was refluxed in a boiling-water bath for $90 \mathrm{~min}$. The resulting solution was mixed with $60 \mathrm{ml}$ of ethanol; the mixture was kept at $-20^{\circ} \mathrm{C}$ for $24 \mathrm{hr}$ and centrifuged. The supernatant was concentrated to dryness. The dried material was dissolved in $1 \mathrm{ml}$ of water and put on a column $(1.5 \times 100 \mathrm{~cm})$ of Bio-Gel P-2 operated at $50^{\circ} \mathrm{C}$, then filtered through the column with water. Fractions of $1.3 \mathrm{ml}$ each were collected and assayed for carbohydrate. Tubes $38 \sim 50$ (fraction F), 69 71 (E), $72 \sim 76$ (D), $77 \sim 81$ (C), $82 \sim 87$ (B), and 89 95 (A) were separately combined and concentrated, each concentrate being rechromatographed on the same column. After freeze-drying, fractions $A$ to $F$ were obtained in a yield of $21.1,5.0,3.0,2.1,0.5$, and $35.0 \mathrm{mg}$, respectively.

\section{RESULTS}

\section{Isolation of an acidic arabinoxylan $(A-A X)$}

The polysaccharide fraction HC-IB-6, obtained from cell walls of immature barley plants, contained arabinose, xylose, glucose, and glactose in a molar ratio of $36.2: 54.1$ : $3.7: 6.3$ as neutral sugar components as described previously. ${ }^{1}$ When fraction HC-IB-6 was chromatographed on DEAE-Cellulose (acetate form), it gave seven carbohydrate fractions, HC-IB-6-i to -vii (Fig. 1). Since the yield of fraction HC-IB-6-iv eluted with $0.5 \mathrm{M}$ potassium acetate was much higher than those of any other fractions and neutral 


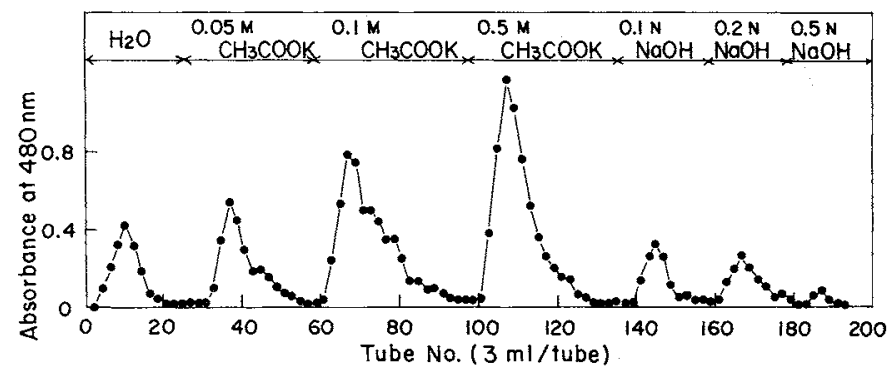

FIG. 1. Chromatography on DEAE-Cellulose of a Polysaccharide Fraction HC-IB-6 Obtained from Cell Walls of Immature Barley Plants.

HC-IB-6 ( $500 \mathrm{mg}$ in $50 \mathrm{ml}$ of water) was put on a column $(1.5 \times 25 \mathrm{~cm})$ of DEAE-Cellulose (acetate form). The column was eluted stepwise with water, potassium acetate, and sodium hydroxide. Tubes $1 \sim 25,26 \sim 58$, $59 \sim 97,98 \sim 135,136 \sim 158,159 \sim 178$, and $179 \sim 200$ were separately combined to give fractions HC-IB-6-i to -vii.

Table I. Yields and Neutral Sugar Composition of Subfractions ObTained from Fraction HC-IB-6 By DEAE-Cellulose CHROMATOGRAPHY

\begin{tabular}{|c|c|c|c|c|c|}
\hline \multirow{2}{*}{ Fraction ${ }^{\mu}$} & \multirow{2}{*}{$\begin{array}{l}\text { Yield }^{b} \\
(\mathrm{mg})\end{array}$} & \multicolumn{4}{|c|}{$\begin{array}{l}\text { Neutral sugar composition } \\
\qquad(\mathrm{mol} \%)\end{array}$} \\
\hline & & Ara & Xyl & Glc & Gal \\
\hline HC-IB-6-i & 21 & 31.4 & 59.2 & 1.7 & 7.7 \\
\hline$-\mathrm{ii}$ & 42 & 31.9 & 60.2 & trace & 7.8 \\
\hline -iii & 151 & 33.8 & 60.9 & 0.7 & 4.6 \\
\hline -iv & 217 & 30.8 & 61.7 & 1.3 & 6.2 \\
\hline$-\mathrm{V}$ & 14 & 19.1 & 53.2 & 9.0 & 18.6 \\
\hline$-v i$ & 10 & \multicolumn{4}{|c|}{ N.D. ${ }^{c}$} \\
\hline$-v i i$ & 10 & \multicolumn{4}{|c|}{ N.D. ${ }^{c}$} \\
\hline
\end{tabular}

a See Fig. 1.

$b$ From HC-IB-6 of $500 \mathrm{mg}$ dry weight.

c Not determined.

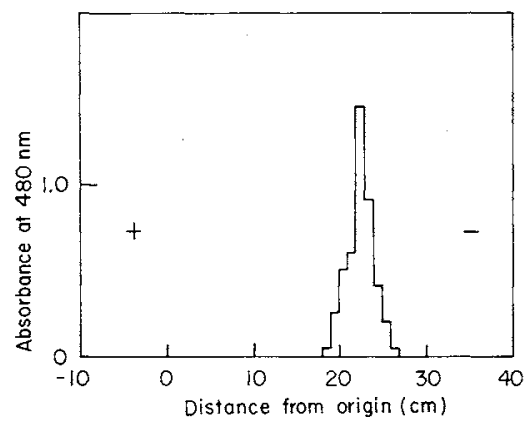

FIG. 2. High Voltage Paper Electrophoresis of A-AX.

Electrophoresis was done on Toyo GA-100 glass filter paper at $1350 \mathrm{~V}$ for $70 \mathrm{~min}$ with $0.1 \mathrm{M}$ sodium tetraborate (pH 9.3). sugar composition of fraction HC-IB-6-iv was not very different from those of any other fractions (Table I), fraction HC-IB-6-iv was designated as acidic arabinoxylan (A-AX) and studied further. A-AX was homogeneous by high voltage paper electrophoresis (Fig. 2), and also by gel filtration on a calibrated Sepharose CL-6B column, and its average molecular weight was about $5.0 \times 10^{5}$. It had $[\alpha]_{\mathrm{D}}-66^{\circ}(c=1.1$, in water $)$.

\section{Structural characterization of $A-A X$}

1. Analysis of acid hydrolyzate of $A-A X$. Acid hydrolysis of A-AX (15 mg) and then chromatography on Dowex-1 (acetate form) of the hydrolyzate yielded neutral $(11.4 \mathrm{mg})$ and acidic (1.4 mg) sugar fractions. The former was shown by GLC on column (a) to be composed of xylose, arabinose, galactose, and glucose in a molar ratio of $62: 31: 6: 1$. The latter was shown by paper chromatography (method B) to be composed of a sugar having $R_{\mathrm{xy} 1} 0.30$, glucuronic acid, and galacturonic acid (Fig. 3). The sugar having $R_{\mathrm{xyl}} 0.30$ (about $0.5 \mathrm{mg}$ ), which was obtained from strips ( $6 \sim 8.5 \mathrm{~cm}$ from origin) by elution with water, followed by freeze-drying of the eluate, was methylated by the method of Hakomori. The uronic acid residue in the sugar, esterified in the methylation reaction, were reduced with lithium alminium hydride ${ }^{9)}$ and the primary hydroxyl group formed from the uronic acid 


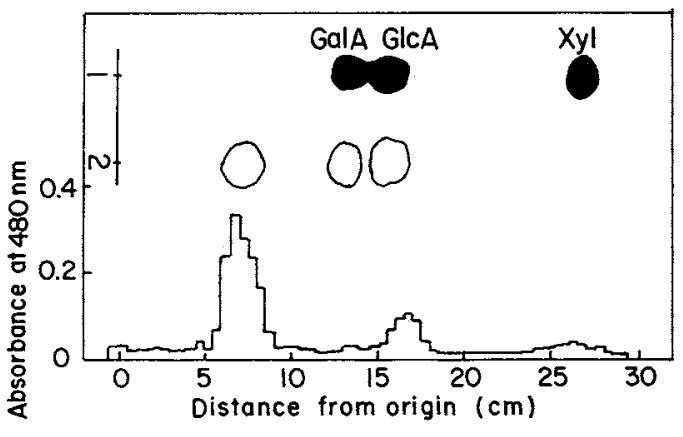

FIG. 3. Paper Chromatogram of Acidic Sugars Obtained from Acid-hydrolyzate of A-AX.

A mixture of acidic sugars (1.4 mg) obtained from an acid hydrolyzate of A-AX was chromatographed on Toyo No. 50 filter paper (method B). After development, the filter paper was cut into strips. Each strip was soaked in $1 \mathrm{ml}$ of water, heated in a boiling-water bath for $5 \mathrm{~min}$ and filtered on Toyo No. 2 filter paper. The carbohydrates in the filtrates were measured by the phenol-sulfuric acid method. Upper part shows a guide strip treated with alkaline silver nitrate ( 1 , authentic sugars; GlcA, glucuronic acid; GalA, galacturonic acid; X, xylose; 2, sample).

residue was methylated by the method of Hakomori. The fully methylated neutral sugar thus prepared was hydrolyzed and converted into the corresponding alditol acetates. Analysis of the partially methylated alditol acetates by GLC on column (b) found nonreducing terminal glucose $(55 \%)$ and 2 - or 4 linked xylose $(45 \%)$ in the methylated sugar. Accordingly, the original acidic sugar having $R_{\mathrm{Xyl}} 0.30$ was considered to be glucuronosyl$(1 \rightarrow 2)$-xylose. The molar ratio of glucuronosyl-xylose, glucuronic acid, and galacturonic acid was calculated to be $60: 40$ : trace from paper chromatography (Fig. 3).

From these results, the molar ratio of $x y-$ lose, arabinose, galactose, glucose, glucuronic acid, and galacturonic acid in A-AX is $59: 28: 5: 1: 8:$ trace.

2. Methylation analysis. Methylation analysis showed that 2,3,5-tri- $O$-methyl-arabinose $(25.5 \%), 2,3,4$-tri-O-methyl-xylose $(2.8 \%), 2,3$ di- $O$-methyl-xylose $(33.3 \%)$, and $2-$ and/or 3 mono- $O$-methyl-xylose $(28.7 \%)$ were prominent structural units in the methylated AAX (Fig. 4). The result suggests that A-AX is comprised mostly of a backbone containing

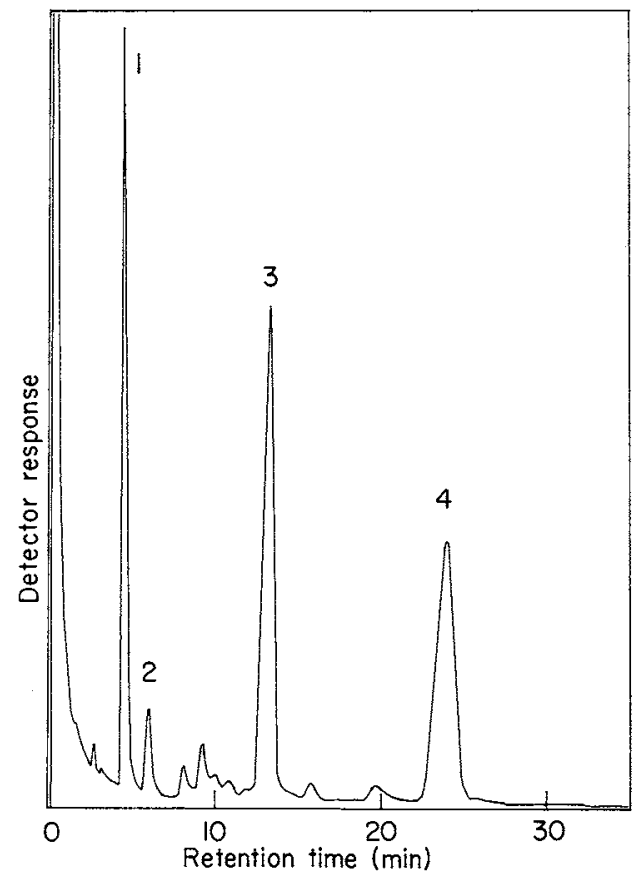

FIG. 4. Gas Chromatogram of the Partially Methylated Alditol Acetates Obtained from the Acid Hydrolyzate of the Methylated A-AX.

The sample was analyzed on column (b) at $172^{\circ} \mathrm{C}$ at a nitrogen flow rate of $15 \mathrm{ml} / \mathrm{min}$. Peaks $1,2,3$, and 4 are 2,3,5-Me $\mathrm{M}_{3}$-Ara (2,3,5-tri- $O$-methyl-1,4-di-O-acetyl-arabinitol), 2,3,4- $\mathrm{Me}_{3}-\mathrm{Xyl}, 2,3-$ and/or 3,4-Me $-\mathrm{Xyl}$ and 2and/or $3-\mathrm{Me}_{1}-\mathrm{Xyl}$, respectively.

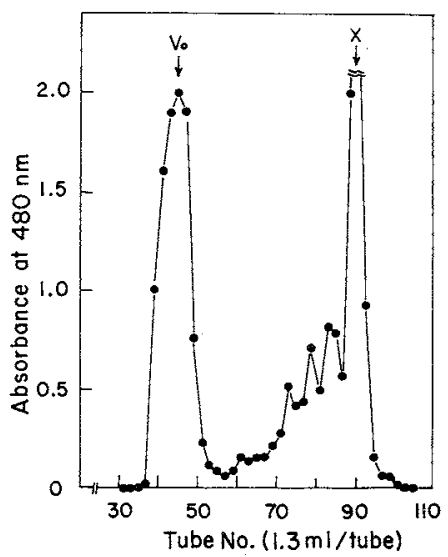

FIG. 5. Chromatography on Bio-Gel P-2 of Partial Acid-hydrolyzate of A-AX.

Partial acid-hydrolyzate of A-AX was put on a column $(1.5 \times 100 \mathrm{~cm})$ of Bio-Gel P-2 operated at $50^{\circ} \mathrm{C}$, followed by filtration through the column with water. The arrows in the figure indicate the elution positions of Blue dextran $(V o)$ and xylose $(X)$ used for calibration. 
Table II. Yields, $R$ V Values, Products of Complete Acid-hydrolysis, and Results of Methylation Analysis of Oligosaccharides B to E Obtained from A-AX by Partial Acid-hydrolysis

\begin{tabular}{|c|c|c|c|c|c|}
\hline \multirow{2}{*}{ Oligosaccharide } & \multirow{2}{*}{$\begin{array}{l}\text { Yield }^{\alpha} \\
\text { (mg) }\end{array}$} & \multirow{2}{*}{$R f^{b}$} & \multirow{2}{*}{$\begin{array}{c}\text { Product }{ }^{c} \text { of } \\
\text { complete acid- } \\
\text { hydrolysis }\end{array}$} & \multicolumn{2}{|c|}{ Methylation analysis $(\mathrm{mol} \%)^{d}$} \\
\hline & & & & 2,3- and/or 3,4- $\mathrm{Me}_{2}-\mathrm{Xyl}$ & $2,3,4-\mathrm{Me}_{3}-\mathrm{Xyl}$ \\
\hline OS-B & 5.0 & 0.50 & Xylose & 48.8 & 51.2 \\
\hline $\mathrm{OS}-\mathrm{C}$ & 3.0 & 0.30 & Xylose & 65.6 & 34.4 \\
\hline OS-D & 2.1 & 0.15 & Xylose & 71.4 & 28.6 \\
\hline OS-E & 0.5 & 0.06 & Xylose & 81.0 & 19.0 \\
\hline
\end{tabular}

a From A-AX of $100 \mathrm{mg}$ dry weight.

${ }^{b}$ Mobility of each oligosaccharide on paper chromatography (method A). The $R f$ values of authentic xylose and $4-O-\beta$-D-xylopyranosyl-D-xylose were 0.71 and 0.50 , respectively.

$c$ Measured by GLC of the alditol trifluoroacetates.

d 2,3- $\mathrm{Me}_{2}-\mathrm{Xyl}=2,3-\mathrm{di}-O$-methyl-1,4-di- $O$-acetyl-xylitol and so on.

some $(1 \rightarrow 4)$-linked xylopyranosyl residues and of single arabinofuranosyl side chains.

3. Analysis of partial acid-hydrolyzate of $A$ $A X$. Partial acid-hydrolyzate of A-AX $(100 \mathrm{mg})$ followed by fractionation of the hydrolyzate by gel filtration on Bio-Gel P-2 afforded six fractions, $\mathrm{A}$ to $\mathrm{F}$ (Fig. 5).

After separation of fraction A (monosaccharide fraction) by preparative paper chromatography (method A), arabinose, xylose, and galactose were obtained in yields of 17.1, 4.0 , and $1.0 \mathrm{mg}$, respectively.

As fractions $\mathrm{B}$ to $\mathrm{E}$, purified by rechromatography on the same Bio-Gel P-2 column, appeared to be homogeneous on paper chromatography, oligosaccahrides in fractions B to $E$ were designated as OS-B (oligosaccharide B), OS-C, OS-D, and OS-E, respectively. Their sugar compositions and results of methylation analysis are summarized in Table II with their yields and $R f$ values. Each oligosaccharide gave only xylose after complete acid hydrolysis. The result of methylation analysis was that the molar ratio of 2,3,4-tri- $O$-methylxylose and 2,3- and/or 3,4-di- $O$-methyl-xylose are approximately $1: 1,1: 2,1: 3$, and $1: 4$ for OS-B, OS-C, OS-D, and OS-E, respectively. OS-B was indistinguishable from authentic 4$O$ - $\beta$-xylopyranosyl-D-xylose on paper chromatography (method A). The $\log R f /(1-R f)$ of xylose, OS-B, $-\mathrm{C}$, -D, and -E, when plotted against the degrees of polymerization, gave a linear regression suggesting that these sugars

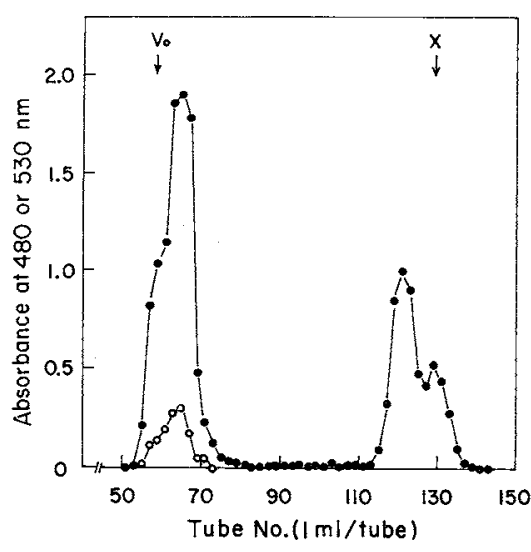

FIG. 6. Chromatography on Bio-Gel P-2 of Fraction F Hydrolyzed with Endo- $\beta$-1,4-xylanase.

Fraction $\mathrm{F}$ (11 mg in $5 \mathrm{ml}$ of $40 \mathrm{~mm} \mathrm{Na}$-acetate buffer, $\mathrm{pH}$ $5.5)$ was incubated with $0.1 \mathrm{mg}$ of Streptomyces sp. endo$\beta$-1,4-xylanase for $24 \mathrm{hr}$ at $40^{\circ} \mathrm{C}$ under a covering of a few drops of toluene. After incubation, the reaction mixture was deionized with Amberlite IR-120 resins ( $\mathrm{H}^{+}$form) and concentrated to a small volume. The concentrate was put on a column $(1.5 \times 150 \mathrm{~cm})$ of Bio-Gel P-2 operated at $50^{\circ} \mathrm{C}$, then filtered through the column with water. Fractions of $1 \mathrm{ml}$ each were collected and assayed for total carbohydrate $\left(A_{480},---\right)$ ) and uronic acid by the carbazole-sulfuric acid method ${ }^{10)}\left(A_{530},-\mathrm{O}-\right.$ ). Tubes $55 \sim 73,115 \sim 125$, and $127 \sim 133$ were separately combined, concentrated to give fractions F-1 (yield: $4.8 \mathrm{mg}$ ), F 2 (1.8 mg), and F-3 (0.7 mg). Paper chromatography (method A) showed that fraction F-2 was xylobiose and F-3 was xylose.

belong to a homologous series.

Fraction $\mathrm{F}$ had $[\alpha]_{\mathrm{D}}-10^{\circ}(c=1.2$, in water $)$ and gave, on acid hydrolysis, xylose, glucuro- 
nic acid, and glucuronosyl-xylose (paper chromatography, method B). Analysis by GLC on column (b) of the partially methylated alditol acetates from the hydrolyzate of the methylated fraction $F$, which was prepared by methylation, reduction with lithium alminium hydride, and remethylation, found nonreducing terminal glucose $(22 \%)$, non-reducing terminal xylose $(11 \%), 2-$ and/or 4-linked xylose $(54 \%)$, and 2,4- and/or 3,4-linked xylose $(12 \%)$ in methylated fraction F. Upon hydrolysis with Streptomyces sp. endo- $\beta$-1,4xylanase, fraction $F$ yielded xylose $(9 \%)$, xylobiose $(25 \%)$, uronic acid-containing oligosaccharides $(66 \%)$ (Fig. 6). These results suggest that the glucuronic acids in fraction $F$ are non-reducing terminal residues.

\section{DISCUSSION}

An acidic arabinoxylan obtained from cell walls of immature barley plants has a linear backbone chain of $\beta-1,4-\mathrm{D}-x y$ lose residues, about $50 \%$ of which were substituted at the 2 and/or 3 position, mainly with arabinofuranose and glucuronic acid residues. The chemical structure of the acidic arabinoxylan is similar to those of arabinoxylans that have been characterized from a number of monocot tissues. ${ }^{1{ }^{18)}}$ McNeil et al. ${ }^{12)}$ reported that barley aleurone arabinoxylan contain no uronosyl residues. It is not certain whether the structural difference between A-AX and barley aleurone arabinoxylan is derived from the difference of barley tissues used. A-AX contained a minor amount of non-reducing ter- minal galactose residue. This must occur as the non-reducing terminal groups of side chains in A-AX, although the details of the structure were not studied.

\section{REFERENCES}

1) Y. Kato, K. Iki and K. Matsuda, Agric. Biol. Chem., 45, 2737 (1981).

2) Y. Kato, K. Iki and K. Matsuda, Agric. Biol. Chem., 45, 2745 (1981).

3) Y. Kato and K. Matsuda, Plant Cell Physiol., 17, 1185 (1976).

4) J. Robyt and D. French, Arch. Biochem. Biophys., 100, 451 (1963).

5) M. Dubois, K. A. Gilles, J. K. Hamilton, P. A. Rebers and F. Smith, Anal. Chem., 28, 350 (1956).

6) T. Imanari, Y. Arakawa and Z. Tamura, Chem. Pharm. Bull., 17, 1967 (1969).

7) S. Hakomori, J. Biochem., 55, 205 (1964).

8) B. Lindberg, Meth. Enzymol., 28, 178 (1972).

9) P. A. Sandford and H. E. Conrad, Biochemistry, 5, 1508 (1966)

10) T. Bitter and H. M. Muir, Anal. Biochem., 4, 330 (1962).

11) D. J. Mares and B. A. Stone, Aust. J. Biol. Sci., 26, 813 (1973).

12) M. McNeil, P. Albersheim, L. Taiz and R. L. Jones, Plant Physiol., 56, 64 (1975).

13) S. Wada and P. M. Ray, Phytochemistry, 17, 923 (1978).

14) J. M. Labavitch and P. M. Ray, Phytochemistry, 17, 933 (1978)

15) E. Maekawa, Agric. Biol. Chem., 39, 2291 (1975).

16) N. Shibuya, A. Misaki and T. Iwasaki, Agric. Biol. Chem., 47, 2223 (1983).

17) Y. Kato and D. J. Nevins, Plant Physiol., 75, 759 (1984).

18) K. C. B. Wilkie, "Advances in Carbohydrate Chemistry and Biochemistry," Vol. 36, Academic Press, New York, 1979, p. 215. 